\title{
Species diversity and diversity profiles: Concept, measure- ment, and application to timber and range management
}

\author{
CLIFFORD E. LEWIS, BENEE F. SWINDEL, AND GEORGE W. TANNER
}

\begin{abstract}
The concepts and use of several diversity assessments are presented and applied to a practical situation. Burning, mechanical methods of site preparation, and cattle grazing are common disturbances in forests of the South. Their influence on plant diversity indices are examined in a longleaf-slash pine forest of north Floridn. Species richneas, Shannon's index, and Simpaon's index showed increases in diversity shortly following burning and site preparation and a trend toward pre-treatment conditions after 6 years. Deferred-rotation grazing systems had no infuence. Comparative diversity profiles showed similar trends but were more informative by providing both qualtative and quantitative information. These techniques are useful for assessing community responses to management practices, that is, they are effective methods for understanding the impacts of forest management and range management practices on plant community structure and succession.
\end{abstract}

Key Words: apecies richness, Shannon's diversity index, Simpson's diversity index, comparative diversity profiles, plant succession, pine-wiregrass vegetation

Literature on the measurement of species diversity is voluminous. Many indices have been proposed, and there has been much debate concerning their use and meaning. Analogous measurements appear in ecology, genetics, linguistics, information theory, and economics. Fortunately, significant theoretical advances have recently appeared in the ecological literature (e.g. Grassle et al. 1979). Patil and Taillie (1982) proposed a compelling definition of species diversity and showed unified, intuitive motivations for the most popular indices along with their relatedness to measures of rarity. These authors and others (e.g. Solomon 1979, Taillie 1979) introduced concepts of intrinsic diversity orderings. When intrinsic orderings exist between 2 communities, any diversity index will agree with the indicated ordering, so these orderings are index free.

Some forest and range management practices (especially clearcut harvesting with intensive site-preparation and range improvement through chopping or discing) conjure vivid images of ecosystem destruction. Hence, many conservation and environmental groups have suggested a need for assessment of the effects of such practices on species diversity. Therefore, we need better tools for assessing and presenting the impacts of management practices on community structure.

Indeed, the National Forest Management Act of the United States [Federal Register 44(181), 219.13(6)] requires that managed practices maintain the diversity of forest ecosystems as demonstrated by quantitative comparisons of the diversities of natural and managed forests. The Act is based not only on aesthetic preferences, but on sound biological principles as well-for example, a diverse community represents a larger gene pool, and is less susceptible to devastation by catastrophic events such as pest epidemics.

In this paper we analyze recent data from integrated pinegrazing management research to determine trends in species occurrence, cover, and certain treatment effects on such trends using

\footnotetext{
Authors are range scientist and research forester, USDA-Forest Service, and associate professor, Department of Wildlife and Range Sciences, University of Florida, Gainesville 32611 .

Manuscript accepted 24 May 1988.
}

diversity indices and comparative diversity profiles.

\section{Analytical Methods}

Patil and Taillie (1982) showed that species diversity should be defined as average (community) species rarity and that familiar indices each measure average rarity. Thus, if we denote

$$
\begin{aligned}
& a_{i}=\text { abundance of } i^{\text {th }} \text { species }(i=1,2, \cdots, s) \text { in a community } \\
& \text { containing s species, } \\
& p_{i}=a_{i} / \sum_{i=1}^{s} a_{i}=\text { proportional abundance, and } \\
& \mathbf{R}\left(p_{i}\right)=\text { a measure of rarity based on proportional abundance, }
\end{aligned}
$$

then average species rarity for the community is simply

$$
\Delta=\sum_{i=1}^{s} p_{i} R\left(p_{i}\right) \text {. }
$$

Now taking $R\left(p_{i}\right)$ to be, respectively,

$$
\begin{aligned}
& \mathbf{R}_{\mathbf{c}}\left(p_{i}\right)=\left(1-p_{i}\right) / p_{i}, \\
& \mathbf{R}_{\mathrm{eb}}\left(\mathbf{p}_{i}\right)=-\log p_{i} \text {, and } \\
& \mathbf{R}_{\mathrm{ei}}\left(\mathbf{p}_{i}\right)=1-\mathbf{p}_{i}
\end{aligned}
$$

and computing average rarity, we have

$$
\begin{aligned}
& \Sigma p_{i} R_{c}\left(p_{i}\right)=\Delta_{c}=s-1 \quad=\text { species count, } \\
& \Sigma p_{i} R_{e h}\left(p_{i}\right)=\Delta_{e h}=-\sum_{i=1}^{s} p_{i} \log p_{i}=\text { Shannon's index, and } \\
& \Sigma p_{i} R_{\text {ei }}\left(p_{i}\right)=\Delta_{d i}=1-\sum_{i=1}^{s} p_{i}^{2}=\text { Simpson's index. }
\end{aligned}
$$

Whittaker (1975) did diversity analyses via importance-value curves obtained by ranking the proportional abundances so that

$$
\mathrm{p}_{1} \geq \mathrm{p}_{2} \geq \cdots \geq \mathrm{p}_{\mathrm{i}} \geq \cdots \geq \mathrm{p}_{\mathrm{i}}
$$

and plotting these $p_{i}$ against rank order, i.e., plotting the points

$$
\begin{aligned}
& \left(1, p_{1}\right) \\
& \left(2, p_{2}\right) \\
& \left(3, p_{3}\right)
\end{aligned}
$$

Comparative diversity profiles (Taillie 1979, Patil and Taillie 1982, Swindel et al. 1987) compare diversities in 2 communities based on plottings of left tail sums of ranked proportional abundances from 2 communities against each other. Given 1 community described by data [1] and another described by

$$
p_{1}^{\prime} \geq p_{2}^{\prime} \geq \cdots \geq p_{i}^{\prime} \geq \cdots \geq p_{i}^{\prime}
$$

(the $k^{\text {th }}$ tail sums are then $p_{1}+p_{2}+\cdots p_{k}$ and $p_{1}^{\prime}+p_{2}^{\prime}+\cdots+p_{k}^{\prime}$ for community [1] and [2], respectively), the comparative diversity profile consists of the points

$$
\begin{aligned}
& \left(p_{1}, p_{1}^{\prime}\right) \\
& \left(p_{1}+p_{2}, p_{1}^{\prime}+p_{2}^{\prime}\right) \\
& \left(p_{1}+p_{2}+p_{3}, p_{1}^{\prime}+p_{2}^{\prime}+p_{0}^{\prime}\right)
\end{aligned}
$$

If these points all plot below the diagonal of a unit square then the second community is intrinsically more diverse (Patil and Taillie 1982), and any diversity index will agree with this ordering. (Points all above the diagonal imply the converse, index-free, diversity ordering.) If the profile crosses the diagonal, then the 2 communities are not intrinsically ordered, and different diversity indices can then disagree on the diversity ordering between the $\mathbf{2}$ communities. 


\section{Effects of Pine Management and Grazing Management on Species Diversity}

\section{Study Site}

The experimental area was on 73 ha of the University of Florida's Austin Cary Memorial Forest, northeast of Gainesville, Florida, which was occupied by a natural stand of 50-year-old slash pine (Pinus elliottii Engelm.) and longleaf pine ( $P$. palustris Mill.). The understory was dominated by common gallberry [Ilex glabra (L.) A. Gray)] and saw-palmetto [Serenoa repens (Bartr.) Small] with few herbaceous plants. Bracken fern [Pteridium aquilinum (L.) Kuhn.)] and pineland threeawn (Aristida stricta Michx.) were the most common herbs. Various bluestem grasses (Andropogon and Schizachyrium spp.), panicum grasses (Panicum spp.), lowpanicum grasses (Dichanthelium spp.), lopside indiangrass [Sorghastrum secundum (Ell.) Nash], and a number of composites occurred sporadically over the area.

The climate is subtropical and humid with long, hot summers and short, mild winters. The frost-free period averages 276 days. Annual rainfall is $140 \mathrm{~cm}$ with half falling during June through September.

Soils on most of the area are siliceous, hyperthermic sands. The acidic sands contain an organic stain layer between 41 to $61 \mathrm{~cm}$ and a clay layer at about $109 \mathrm{~cm}$.

Twenty-eight 1-ha test pastures were selected for treatments (Lewis et al. 1988). The remaining area was divided into 3 holding units for cattle when they were not grazing the test pastures. Twenty-two test pastures and the holding units were clear-cut during the fall and winter of 1976-77, then were double-chopped with a roller-drum chopper during August and September 1977, and slash pine was planted during the winter of 1977-78. The 6 pastures left in natural stands were prescribed burned with a fairly hot fire during January 1978 and again in 1981. Cattle grazed in test pastures from May 1979 through December 1983.

\section{Treatments}

The study was a factorial experiment of 4 timber conditions and 4 grazing schemes in a randomized complete-block design with 2 blocks. Timber conditions were (1) natural stands of 50-year-old pines; (2) clear-cut, chop, no planting of pines (open); (3) clear-cut, chop, plant slash pine $(1,112$ trees $/$ ha) at a spacing of $2.4 \times 3.7 \mathrm{~m}$ (single rows); and (4) clear-cut, chop, plant slash pine (1,112 trees/ ha) in a double-row configuration at $1.2 \times 2.4 \mathrm{~m}$, with $12.2 \mathrm{~m}$ between double rows. Grazing treatments compared no-grazing with 3 deferred-rotation systems: (1) graze 45 days then rest the pasture for 3 months before grazing again; (2) graze 30 days with 4 months rest; and (3) graze 30 days with 6 months rest. Fourteen treatment combinations were randomly located in each block.

\section{Measurements}

Data were collected from line transects: frequency of occurrence for herbaceous plants and foliar cover for woody plants. Three 30.5-m line transects were randomly placed in each test pasture at $45^{\circ}$ angles to the tree rows. To measure herbaceous plants each transect was divided into 100 segments of $30.5 \mathrm{~cm}$. A species was tallied as present if any living part of the plant intercepted a segment between ground level and $1.5 \mathrm{~m}$. Foliar cover of woody plants was determined by measuring the crown intercept of all woody vegetation by species along the line transect. Woody plants less than $1.5 \mathrm{~m}$ aboveground were measured to the nearest centimeter while those above $1.5 \mathrm{~m}$ tall were measured to the nearest $30 \mathrm{~cm}$. Plant measurements were made in the fall of 1976 before disturbance and subsequently in the fall of 1978, 1980, 1981, and 1983.

\section{Effects on Common Diversity Indices}

Using frequency of occurrence as a measure of the abundance of each herbaceous species, we computed species count, Shannon's index, and Simpson's index as 3 commonly employed measures of average species rarity. There were no significant differences due to the deferred-rotation treatments (Lewis et al. 1988) so these data were combined. To illustrate the overall results, data from the chopped-only treatment for frequency of occurrence of herbaceous species were used to compare diversity (Fig. 1). It is evident that herbaceous species diversity increased following site disturbance (for about 4 years) then declined. These same trends occurred whether disturbed by prescribed fire; harvest and chopping; harvest, chopping, and normal planting; or harvest, chopping, and double-row planting of pines. This trend is in agreement with
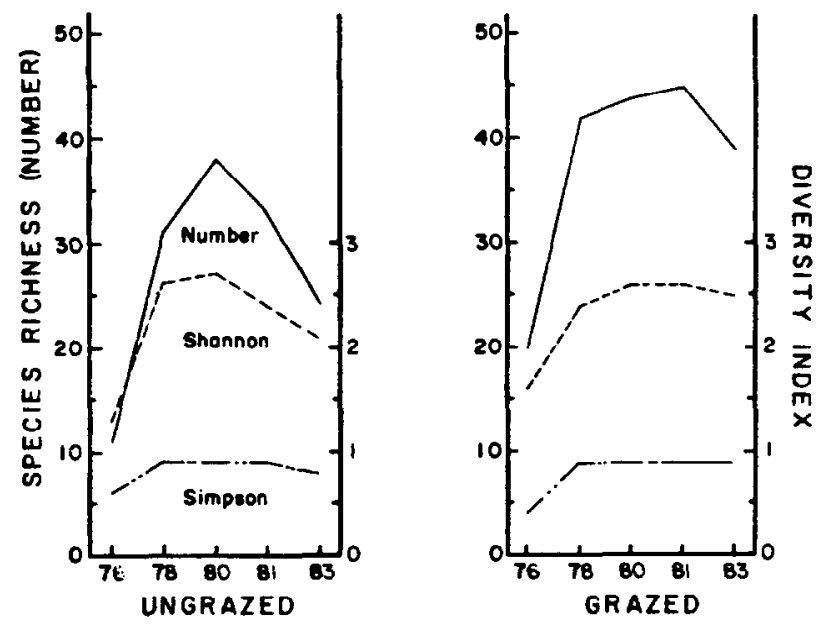

Fig. 1. Species count, Shannon's index, and Simpson's index of herbaceous plant occurrence in a community before and for several years after clear-cut harvesting and chopping, with and without grazing.

responses following disturbance on other sites (Swindel et al. 1984). Shannon's index effectively illustrates the influence on both number of species and the density (or occurrence) of each species.

Using foliar cover as a measure of the abundance of each woody species, Shannon's index displays the greater diversity resulting from mechanical disturbance as compared to prescribed burning (Fig. 2).
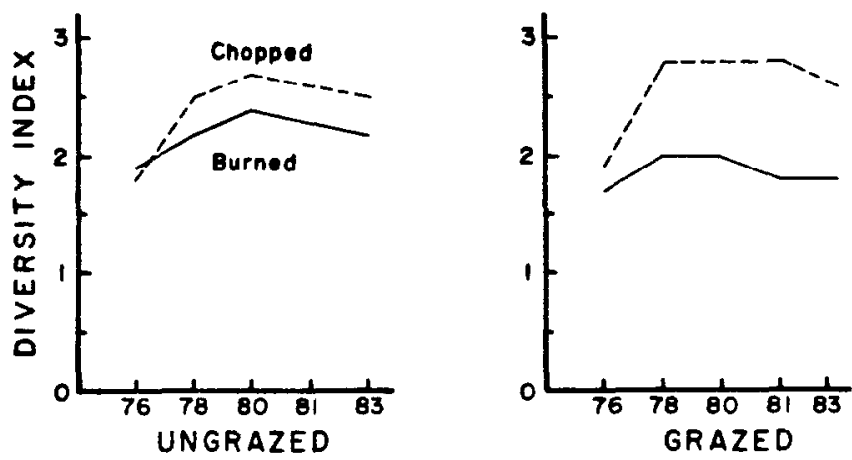

Fis. 2. Shannon's index for cover of woody plants in a community before and for several years after disturbance by burning or by clear-cut harvesting and chopping, with and without grazing.

Diversity tended to decrease after about 4 years as with the herbaceous component. Simpson's index showed similar trends but of less magnitude as with herbaceous species. However, there were few changes in species of woody plants present on the area. The increase in diversity among woody plants came about from increased abundance of rare species while the herbaceous community became more diverse by both adding new species and transferring abundance (Patil and Taillie 1982).

Changes in the diversity of various components of a community can be measured and evaluated by these techniques. For example, we examined the responses to treatments of grasses, forbs, shrubs, and all herbaceous plants as separate components. There were small differences between grazing treatments and the trends were 


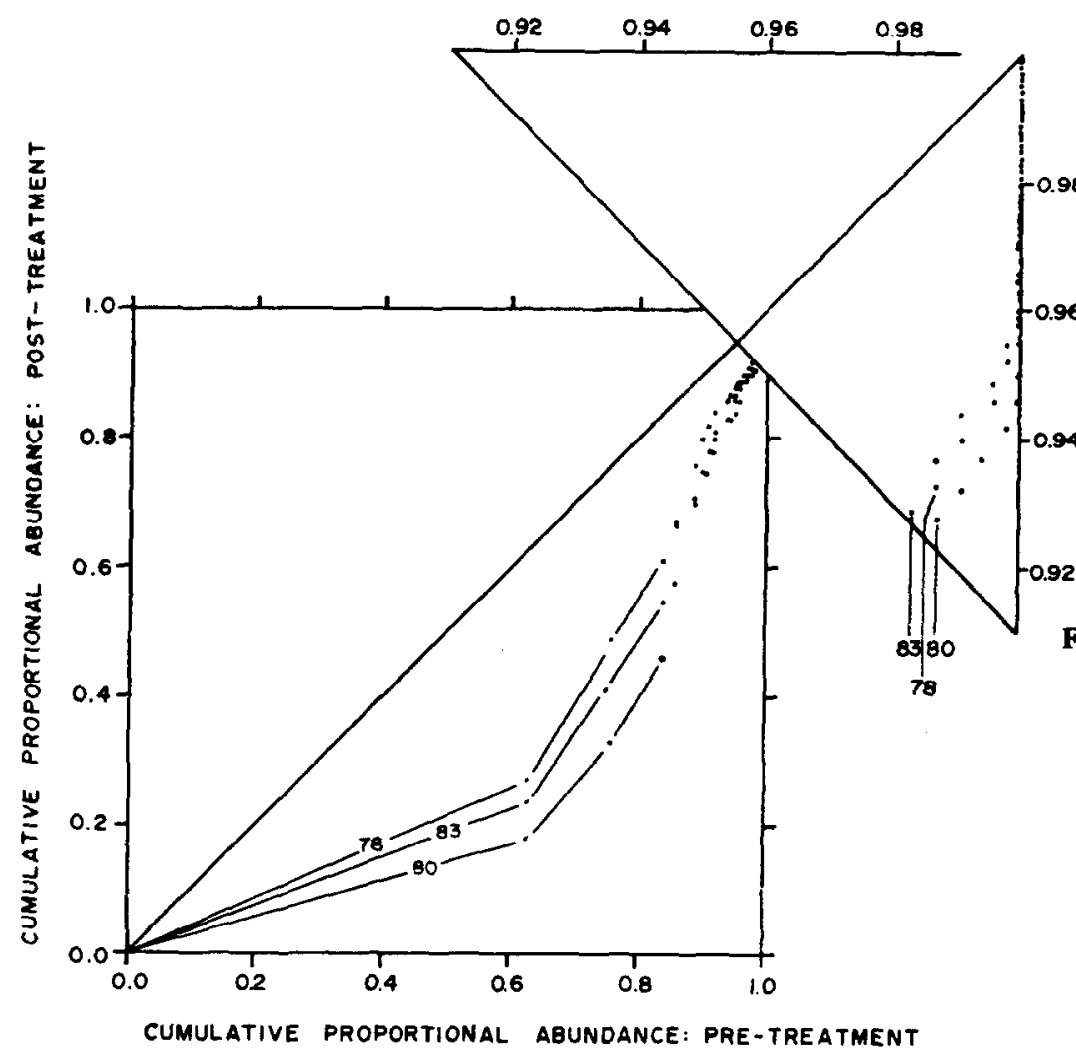

Fig. 3. Diversity profiles comparing post-treatment communities to the pretreatment community for occurrence of herbaceous species in the clearcut, chopped, and not-replanted treatment. The upper right-hand corner is shown at $10 \times$ magnification.

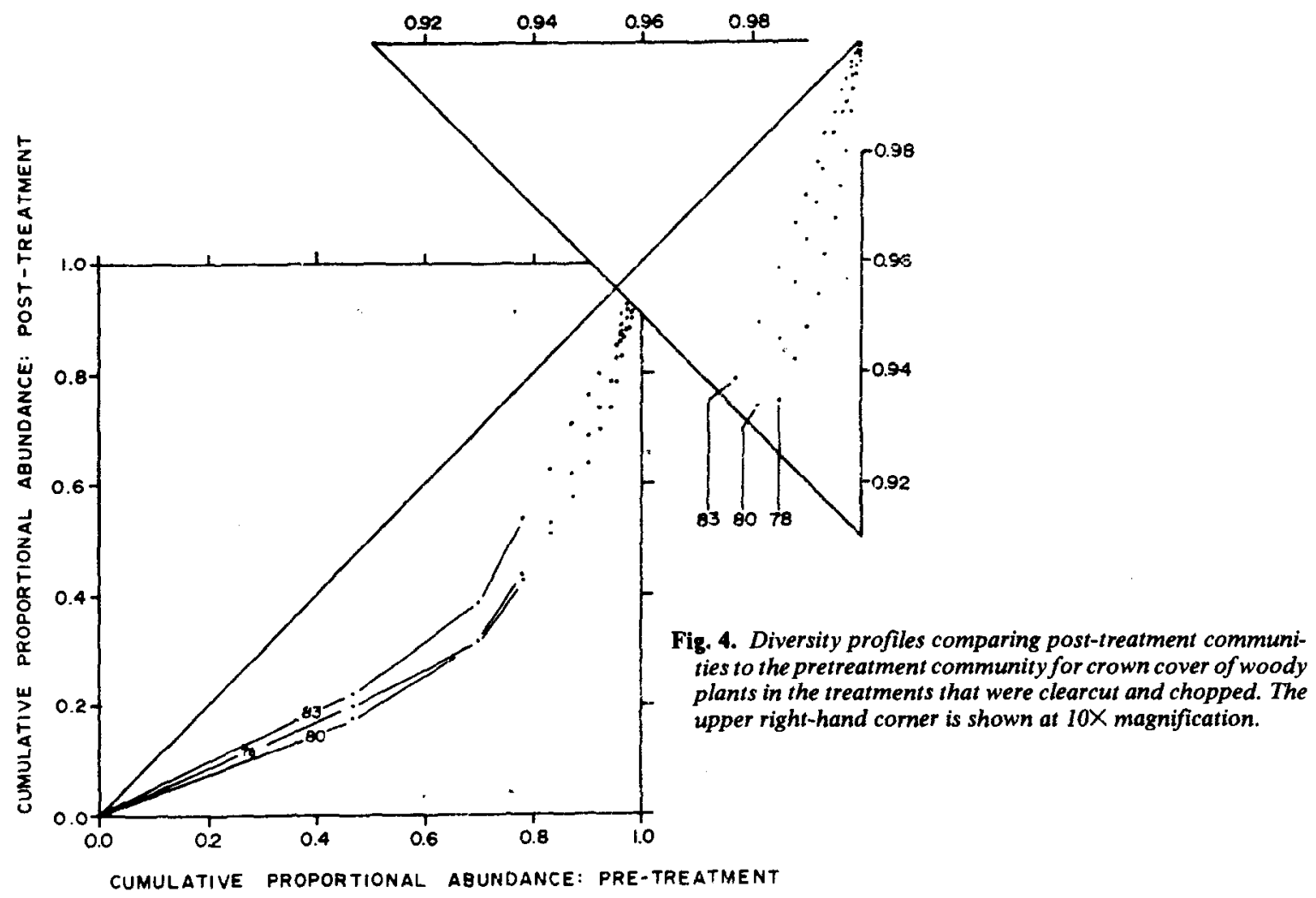

similar to those in Figures 1 and 2.

Diversity changes were less pronounced following fire than following substantial mechanical site disturbance. The former treatment has long been recognized in the South as a tool for both forage and wildlife habitat improvement (widely deemed to be positively correlated with increased diversity). The latter treat- ments are sometimes thought to produce only monocultures of slash pine plantations and are less widely recognized as methods for improving wildlife habitat quality and forage production. However, these results and others (Lewis et al. 1984, Swindel et al. 1987 ) indicate improvement in wildlife habitat and forage yields are common. 


\section{Effects on Diversity Profiles}

Comparative diversity profiles for herbaceous vegetation (Fig. 3) and woody vegetation (Fig. 4) used the pretreatment community (1976) as a baseline to which post-treatment communities were compared for 1978,1980 , and 1983. The most obvious feature is that all 3 comparative profiles plot below the diagonal. This shows that post-treatment plant communities were intrinsically more diverse than the plant communities prior to disturbance.

Temporal trends in diversity are also evident. For occurrence of herbaceous plants (Fig. 3), the major increase in diversity occurred within a year after disturbance (by 1978) but continued to increase over the next 2 years. However, by 6 years after disturbance there was a return of diversity toward the pretreatment condition (Figs. 1 and 2). Trends in diversity of cover for woody species (Fig. 4) give additional information on the community response when the more common species (left-tail) and rare species (right-tail) crossed over in the relative ordering. In other words, the rare species contributed the most to diversity of the community in 1978 while there was an additional increase in the diversity of common species in 1980.

Information on other ecological properties of communities can be derived from comparative diversity profiles as compared to diversity indices. Specifically, the left-tail points indicate the contributions of common species while the right-tail points indicate the proportion of rare species. For example, by counting the tick marks along the $x$-axis in Figure 3, it can be seen that only 2 herbaceous species contributed $80 \%$ of the abundance and that 19 species comprised the remaining $20 \%$ of the community in 1976 (base-line). Then by counting the number of points along the $y$-axis in any year, the number of common species contributing to this $80 \%$ is seen to be 6 in 1978 and 8 in both 1980 and 1983. It is impossible to determine the exact number of species in the rare category (right-tail) because of the convergence of points. However, if the number of species (richness) in the original data set is known, it is easy to determine the number of species in the rare group. For this data set it was 19, 37, 39, and 32 in 1976, 1978, 1980, and 1983, respectively. These procedures applied to Figure 4 showed there were $3,8,9$, and 7 common woody species and 25,16 , 21 , and 22 rare woody species in 1976, 1978, 1980, and 1983. Since there was no major invasion of new woody species, as occurred with herbaceous species, it becomes clear that the increase in diversity was the result of transferring abundancy among the existing species.

The diversity profiles also reveal interesting information about extremely rare species. By drawing a vertical line from the 0.99 tick mark on the horizontal axis, the contribution of extremely rare species to percent occurrence by herbaceous species and percent cover by woody species can be estimated. The point at which this vertical line intercepts the diversity profile indicates the relative contribution of extremely rare species. This is best illustrated by the woody plants (Fig. 4). Where the cumulative proportional contribution of extremely rare species was $1 \%$ in 1976, it increased to $5.2 \%$ in 1978 . Thereafter, it decreased to $3.1 \%$ and $2.8 \%$ in 1980 and 1983 , respectively. The number of species in these extremely rare categories can be roughly estimated by counting the number of points along each profile to the right of the vertical line. However, this becomes an impossible task when the points fall close together, as in Figure 3. Yet, knowing that only 4 species contributed to this $1 \%$ in 1976 (base-line), it is apparent that many additional species occurred in each post-treatment year. However, the post-treatment cumulative proportional abundance for extremely rare herbaceous species was $6.0 \%$ in $1978,6.8 \%$ in 1980 , and $5.6 \%$ in 1983 . For both plant types, these profiles indicate an ecological trend where plant diversity began to return toward pre-treatment conditions by 6 years after disturbance.

\section{Discussion and Conclusions}

Diversity assessments are useful tools in ecological evaluations. Diversity indices, such as species count, Shannon's index, and Simpson's index have been used for comparing diversity and for determining trends following disturbance. Our evaluations indicate that Shannon's index is especially useful in describing ecological trends. This is probably because it adequately includes both species count and evenness.

Diversity profiles are even more useful for investigating ecological conditions because they not only illustrate intrinsic diversity orderings, they also illustrate other important information about community structure. For example, diversity profiles indicate the relative contribution of abundant species and the relative contribution of rarer species to diversity. At the same time they can show successional trends of a community over time as affected by abundant and rare species.

All of these diversity assessments possess the qualities of being unaffected by size (area) of the community or by the size of the plants. They are also indifferent to species' names while being only concerned with the length of species lists and equitablity of proportional abundance. These characteristics make them especially useful as measures of diversity in meeting requirements of the National Forest Management Act.

Conservationists and wildlife biologists should be especially interested in the use of diversity profiles since the right-tails of these profiles present information on the rare species of the community. Rare species influence the perpetuation of some desirable community components more than do abundant species and are frequently suggested as being required in order to maintain biological diversity. Although these diversity assessments are indifferent to plant names, graphical methods for examining individual species responses to treatment are available (Moore et al. 1982a, 1982b).

Our empirical study of the influence of disturbance either by burning or by harvesting and site preparation in pine-wiregrass vegetation revealed that diversity increased for 2 to 4 years then began to return to pre-treatment levels. Scarce herbaceous species increased rapidly following disturbance but changes in the number of abundant species were limited. By 6 years following disturbance all components were moving slowly toward pre-treatment conditions. These results show that common timber management and grazing management practices do not decrease species diversity. Rather, these disturbances can increase or help maintain diversity in southern forests. This knowledge alleviates much of the concern about environmental degradation. Diversity profiles are especially useful for presenting these results.

\section{Literature Cited}

Grassle, J.F., G.P. Patil, W. Smith, and C. Tallle (ed.) 1979. Ecological diversity in theory and practice. Int. Coop. Publ. House, Fairland, Maryland.

Lewis, C.E., G.W. Tanner, and W.S. Terry. 1988. Plant response to pine management and deferred-rotation grazing in north Florida. J. Range Manage. 41:463-468.

Lewis, C.E., B.F. Swindel, L.F. Conde, and J.E. Smith. 1984. Forage yields improved by site preparation in pine flatwoods of north Florida. South. J. Appl. Forest. 8:181-185.

Moore, W.H., B.F. Swindel, and W.S. Terry. 1982a. Vegetative response to clearcutting and chopping in a north Florida flatwoods forest. J. Range Manage. 35:214-218.

Moore, W.H., B.F. Swindel, and W.S. Terry. 1982b. Vegetative response to prescribed fire in a north Florida flatwoods forest. J. Range Manage. 35:386-389.

Patil, G.P., and C. Taillie. 1982. Diversity as a concept and its measurement. J. Amer. Statis. Assoc. 77:548-561.

Solomon, D.L. 1979. A comparative approach to species diversity. P. 29-35 In: Grassle et al. (ed.), 1979.

Swindel, B.F., L.F. Conde, and J.E. Smith. 1984. Species diversity: concept, measurement, and response to clearcutting and site-preparation. Forest Ecol. Manage. 8:11-22.

Swindel, B.F., L.F. Conde, and J.E. Smith. 1987. Index-free diversity orderings: Concept, measurement, and observed response to clearcutting and site-preparation. Forest Ecol. Manage. 20:195-208.

Taillie, C. 1979. Species equitability: A comparative approach. P. 51-61. In: Grassle et al. (ed), 1979.

Whittaker, R.H. 1975. Communities and ecosystems (2nd ed.). MacMillan, New York, N.Y. 